\title{
VERNACULAR CREATIVITY AND NEW MEDIA: ISTOCKPHOTO*
}

\author{
Deniz YENGIN \\ Istanbul Kültür University, Turkey \\ d.yengin@iku.edu.tr \\ Berna EKIM \\ Maltepe University, Turkey \\ bernaekim@maltepe.edu.tr
}

\begin{abstract}
Globalization or McLuhan's "Global Village" concept is increasingly getting a clearest shape. Along with globalization, communication mediums are also developing. They have the qualities of being digital, interactive, and virtual and are thus "new" mediums of communication. Due to these qualities, communication mediums are changing form and are being used by network societies. These mediums also influence individual creativity due to their interactive use. Individuals can create and share their own visual designs, especially when employing social networks. Creativity differs from person to person, as it does from region to region. In this study, visual designs created with new media will be examined and the concept of vernacular creativity will be defined and explained. The social network istockphoto will be used as an example for analysis. According to this example, this study will be delivered with qualitative and quantitative methods.

Keywords: vernacular creativity, new media, social network, network society, interaction, digitalization, virtuality, istockphoto.
\end{abstract}

\section{INTRODUCTION}

The current era is desrcibed with the terms like information society, technological society, electronic society, digital society, network society, etc. Especially the concepts of network society introduced by Castells and Van Dijk match up clearly with the communication environment in our day. The communication environments of network society are interconnected and these connections speed up the communicational exchange through the networks. An infrastructure of social and media networks takes care the form and organization of information processing and exchange (Van Dijk 2006: 20). So the network society can be defined as a social formation with an infrastructure of social and media networks enabling its prime mode of organization at all levels.

Individuals are coded with the digital charesteristic of the new media via infrastuctures of social and media networks. This coding becomes more evident especially with the use of social networks. Individuals with digital identities in a village surrounded by networks are able to be a part of any social network. It is important to have different features and express one's self through these networks. The distinction factor appears according to the creativity of the individuals. Creativity on the other hand may vary according to the regions. Thus, the concept of vernacular creativity is defined in the study and it is described with respect to the examination of a sample picked in light of this definition.

\section{NEW MEDIA}

The development in the fields of telecommunication and information technology which started in 1990s has led to an increase of the media and communication studies, and thus

\footnotetext{
* Presented on Vizuality Conference: Interactions of Creativity and Images, Vilnius, 2011.
} 
new media theory is born. Especially McLuhan, inventor of the term media, argued that the effects of the electronic revolution in 1950s America were so great as to make educators displaced persons living in a world that has little to do with the one in which they grew up (Littlejohn 2009: 684). The development of mass media has given rise to the introduction of media which may be defined as "new".

Today's communication media is going through a transformation process with the presence of technological developments. The transformation of the communication media is defined with the concept "new". The concept of "new" which means unused and opposite of old, cover both the new and old in the communication media. The "new" goes beyond its meaning by also covering the communication media which is also defined as "old". The new media is increasingly interactive, allowing consumers to choose what information and entertainment resources thet want, when they want it, and in what form (Dizard 1999: 17). Under the light of these definitions the new media is defined as the new, different and distinctive space where individuals actualize, experience the communication process (Yengin 2010: 320).

The definitions of Lister and Manovich analysing and describing the principles of especially new media in communication studies, form a basis for the academic studies. Manovich explains the principles of new media with numerical representation, modularity, automation and variability (Manovich 2001: 27-48). Lister on the other hand categorizes as digitality, interactivity, hypertextual, networked, virtual and simulated (Lister 2003: 9-44). In light of these principles, the most significant feature of the new communication media seems to be code based digitality, interactivity and virtuality. Digitality is the expression of data according to the binary system. Access to data is fast in digital systems. Interactivity is the situation where the user intervenes the content of data. Virtuality is the presentation of the simulation of the reality. The media which bears these features is referred to as new media.

The removal of the space requirement with the new communication media in the last twenty years has facilitated the access of the individuals to the information sources. Especially the social networks draw the attention of the individuals and cause them to spend most of their time in such environments. The individuals who code their identities digitally in such environments gravitate to different fields amid the endlessness information and improve their skills. Especially creativity in new media becomes prominent and this creativity changes from one person to another and from one region to another. As such, the definition of "vernacular creativity" becomes important.

\section{VERNACULAR CREATIVITY}

Information society, a theoretical perspective on advanced capitalism as being predominantly concerned with post-industrial, network economies that have passed through an industrial age into a communications age (Laughey 2007: 201). New media is a term which represents a development rather than describing a specific group of technology or technologies. The publication and broadcasting of all types of communication factors like texts, sounds, videos, graphics, photographs and music, which are all multimedia elements, have been possible through convergence including the new fields which did not allow any access in the past.

Castells's and Van Dijk's description of network society perfectly fits the current period. The individuals who are digitalized in an interconnected and globally and locally braided network society express themselves through the channels of new media and spend most of their time in such environments. Social networks are web based virtual space environments offered to the individuals with the development of internet. In such environments the communication process takes place in a different way such awareness leads to the increase of interaction through the rapid exchange of messages. These environments including personal publication, exchange, conversation, social environment, expression of opinions, tracking, virtual platform and games differ from each other. In such environments especially the exchange of information should be fast and at a high level. A good example to this is Facebook social network with more than half a billion members. In these environments people are able to 
make friends, make observations, share multimedia files, play games, form groups and do business.

Individuals vary with the social networks which are created in internet environment, as popular means of culture. The traditional socializing culture is replaced by the digital based environments. And individuals with the new communication media, display their creativity in order to express themselves to the environments in social networks in a more effective manner.

The word creativity derived from creô in Latin means being creative, the one who has the skill of creating. Creativity requires both skill and ability so it bears the characteristics of variability. The creativity may change from one person to another. It is mainly because of the education, social rules, traditions, moral laws and family. Combination of these different sources lead to creativity. As such, the concept of regionalism gains importance. Various studies have been conducted especially in the fields of linguistics and architecture focusing on vernacular. There are dialects especially in Turkish which arise according to the regions. In such dialects the written form of the Turkish language is same whereas there are differences in the spoken language. Similarly, we may easily see that every society is structurized differently. The structurization in İstanbul seems to be more modern whereas it is more traditional in the rural areas. Therefore, individuals' intercultural exchanges play an important role in the formation of vernacular creativity.

Burgess has studies on regional creativity in digital media. In his phd study, Burgess studies the regional creativity of the photograph in the digital based new media. According to Burges vernacular creativity is the individuals' use of their extraordinary creativity via new media environment which reaches a large mass of people through the effects of creative activism, fandom and game cultures (Burges 2007, 62-73). Vernacular creativity takes places with the conveyance and exchange of cultures.

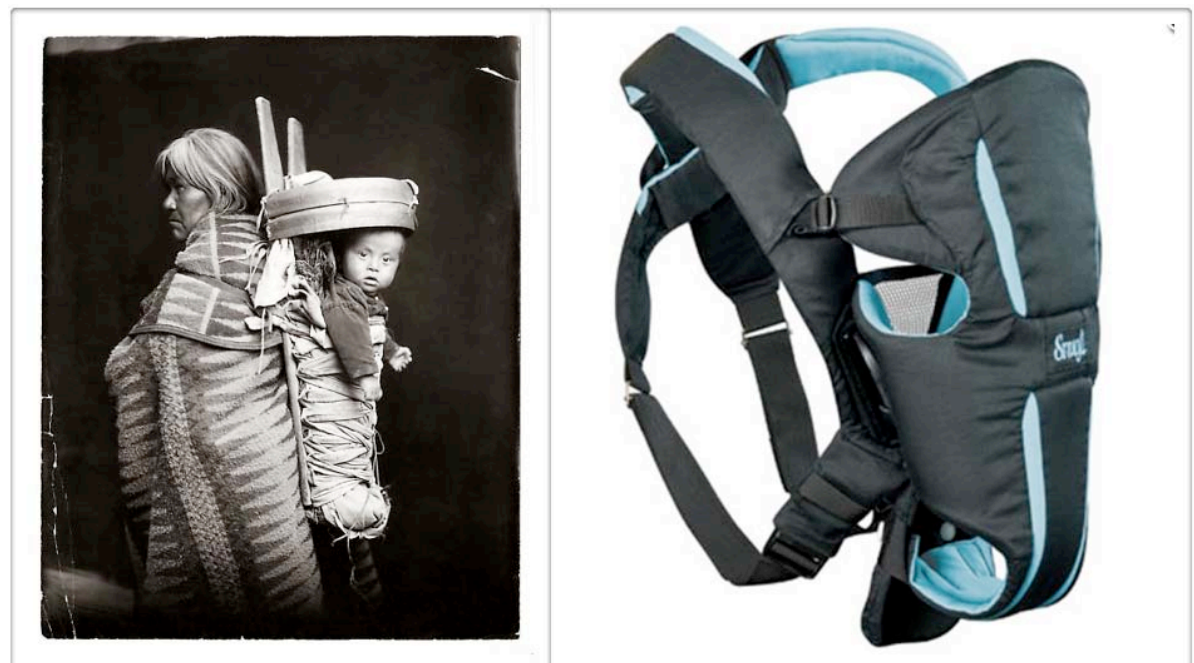

Figure 1: Navajo Indian carrying baby* (left) \& EvenFlo Snugli Carrier** (right)

(* http://aleasemichelle.typepad.com/my weblog/2009/11/native-american-prints-from-thepennington-photo-studio.html ** http://shop.productwiki.com/evenflo-snugli-hug/ )

What draws our attention in Figure 1 is vernacular design. The image on the left represents fully the traditional and regional understanding designed according to the needs of our day. This understanding is produced again and updated today with the same traditional perception without losing its essence. Here the regional appearence is redesigned and adapted to the present time (Vivanc1 \& Verghese 2010). In this context, vernacular creativity means the products which are shaped according to the knowledge acquired based on the individuals' 
education, family relations and environments as well as technology. This concept generates new technocrats especially in the global village surrounded by the networks and brings out technological (digital) based individuals.

\section{METHODOLOGY}

Technological developments lead to the change of form of the communication media. Through such media surrounded by networks, individuals are able to perform any type of sharing with their digital identities and develop their creativity with their variable features. In this study, the regional creativity is examined according to the selected sample. The photograph area in the istockphoto multimedia network portal, which is selected as a sample, is studied and the vernacular creativity in the new media is described through evaluations carried out with quantitative data.

\section{FINDINGS}

Internet is rapidly becoming an integral part of our lives. An up-to-date example to this is the Facebook portal with more than half a billion of users and a number of users which increases each and every day. This use brings out different possibilities enabling individuals to find the environments where they can market their creativity and designs. The most up-todate example of sharing in the multimedia field is istockphoto. Set up in 2001 by Bruce Livingstone, a Canadian entrepreneur, is an online, royalty free, international microstock photography provider operating with the micropayment business model (Wikipedia, 2011). The portal declared a USD 72 million profit for 2007 and paid USD 21 million of this amount to its members. Istockphoto as a new trade model is an international multimedia sharing platform. The randomly selected photographs in the istockphoto portal should be studied by going through the features of the loader, requests, downloading and contents.

\begin{tabular}{|c|c|c|c|c|c|c|c|c|}
\hline & Photo & Uploaded on & Contributor & Member Since & Nation & Job Description & Portfolio Files & Downloads \\
\hline 3 & Big Wash & 06.03 .2010 & Olena Vizerskaya & Feb-10 & Ukraine & Photographer & 324 & 4400 \\
\hline 4 & Seafood Lover & 25.02 .2011 & Michael Krinke & Mar-07 & USA & Photographer & 1130 & 51000 \\
\hline 6 & Young Man Drinking Beer out of Crazy Straw Glasses & 18.05 .2009 & Valentin Casarsa & Apr-05 & Slovenia & Photographer & 6125 & 74000 \\
\hline 7 & Cigarette Addiction & 07.12 .2007 & Perry Gerenday & Dec-06 & USA & Designer & 147 & 1500 \\
\hline 8 & Drip Chain & 16.03 .2011 & Brendan Hunter & Feb-07 & USA & Photographer & 2224 & 2300 \\
\hline 11 & Young Asian Woman Wearing Silver Tubing & 14.02 .2008 & Quavondo & Jan-07 & USA & Photographer & 2762 & 150000 \\
\hline 12 & Lettuce Head & 10.11 .2006 & Byll Williams & Sep-06 & USA & Photographer & 101 & 7800 \\
\hline 13 & Whoops & 17.05 .2006 & Soubrette & Feb-02 & USA & Designer & 882 & 48000 \\
\hline 14 & Man Holding Rosary & 01.07 .2006 & Ladida & Apr- 03 & Greece & Photographer & 1810 & 31000 \\
\hline 15 & Riomaggiore & 18.07 .2006 & Luke Andreson & Mar-06 & USA & Photographer & 10 & 200 \\
\hline 16 & Look into the Light & 03.03 .2006 & Joshua Blake & May-04 & USA & Photographer & 1724 & 140000 \\
\hline 17 & Cruisin & 16.03 .2011 & Andrew Rich & Aug-05 & USA & Photographer & 2162 & 220000 \\
\hline
\end{tabular}

Table 1: List of data about the randomly selected photographs

(Source: http://www.istockphoto.com, 01.03.2011)

The 20 photographs selected as a sample in the istockphoto portal have been selected randomly. There are photographers from different countries as far as the contibutors of the selected photographs are concerned. $75 \%$ of those sharing these photographs are photograph artists. Especially participation from the USA is quite high. Other artists are from Russia, Turkey, Ukraine, Serbia, Slovenia, Romania, Greece, Hungary and South African countries. The commencement of membership of the photograph artists vary in the istockphoto portal which has been operating actively since 2000. The portfolio and the number of the downloaded photographs of the photograph artists from the USA, Russia, Turkey, Ukraine, Serbia, Slovenia, Romania, Greece, Hungary and South Africa are striking. In the portfolio of 20 artists there are 35500 photographs in total. On the average 1775 shareable photographs of the artists are noticeable. The shareability levels of these photographs are pretty high. Each photograph in the portfolio (35500 pieces) has been downloaded for at least 25 times. They have been totally shared 893700 times. The average number of the photographs of each 
photographer that have already been shared is 44685 (Table 1). As such, each of the selected photograph has been shared 25 times on the average and sharing still continues.
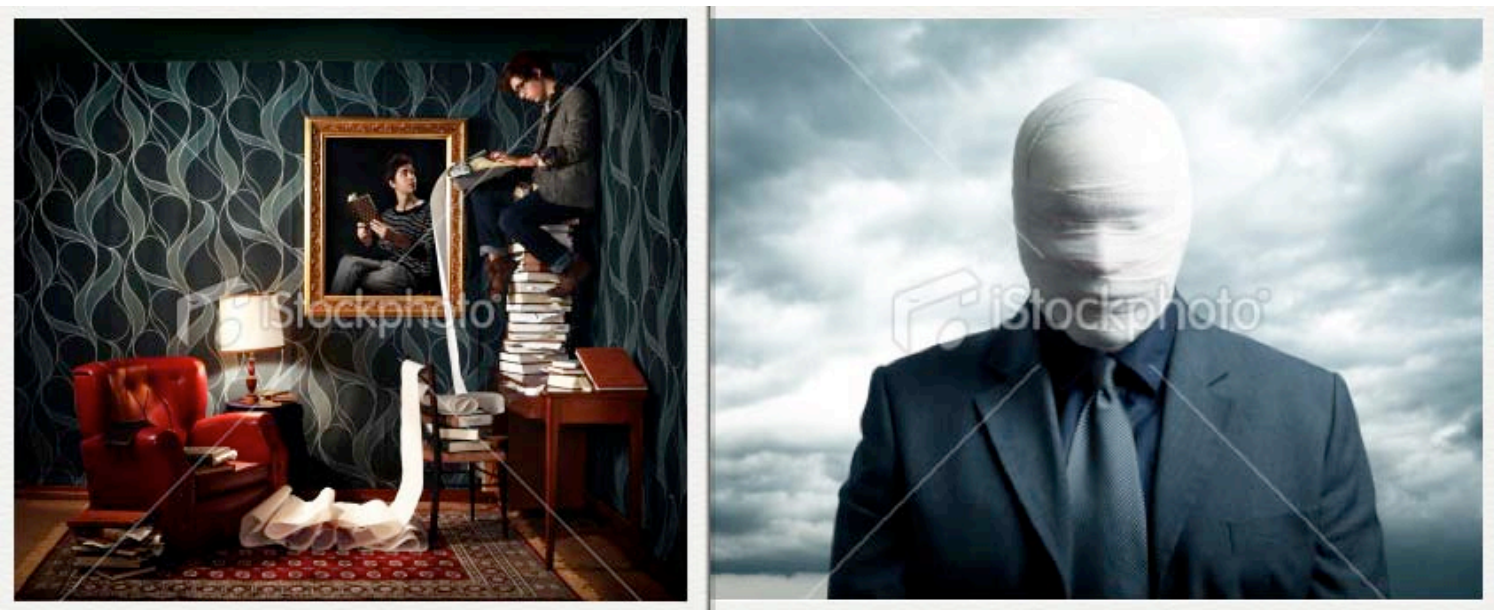

Figure 2: Young Writer with Typewriter* (left) \& Businessman Mummy** (right)

(* http://www.istockphoto.com/stock-photo-15975897-creative-process-young-writerwithtypewriter.php?st $=545 \mathrm{~d} 0 \mathrm{~b} 4$

** http://www.istockphoto.com/stock-photo-14488271businessmanmummy.php?st=ab11a0d)

Morris, an American photographer, who has shared the photograph named "Young Writer with Typewriter" photographs the young writer sitting on a bunch of books by creating a composition in order to underline the difficulties of writing a book and the young artists go through. The Serbian artist sharing the photograph named "Businessman Mummy" photographs a mummified man in the suit in order to express the difficulties of both business life and the individuals go through (Figure 2). Artists exhibit in these photographs regional creativity by making use of cultural traits and their experiences.

It is observed upon the examination of the photographs that the photographers with different nationalities are involved in a fast and active sharing with the other artists. The shareability level of only 20 artists' photographs is high. High sharing level will allow an increase in number of the sharing portals like istockphoto which is qualified as new media. The reason the sharing rates are so high is that the access to the new communication media is easy and it is a system which is open to everyone. Thanks to new media, photograph artists are able to increase their regional creativity and produce interactive works by enjoying the limitlessness of sharing and other cultures.

\section{CONCLUSIONS}

Technological developments accelerated the development of media, and thus the individuals have been a part of such media. Through new media, the regional creativity of the individuals reach large mass of people in a more faster way and it may also vary. The regional creativity which is shaped according to the individuals' knowledge based on education, family relations, environments and technology are reshaped through the new media. Istockphoto muldimedia sharing portal which is dealt with as new media in our study, is a media which allows individuals to share independently by means of regional features of creativity and helps them make financial profits out of these sharings through the new business model. Such media generates new technochtars_especially in the global village surrounded by the networks and brings out technological (digital) based individuals. While the foreign productions in new media are increasing they are shared in a very fast way. Digitilization helps the social networks in photosharing websites like istockphoto to realize convergence. It helps the people with the identical sharing features come together and give rise to creative contents. Individuals' unlimited sharing forms visual sharing revolution by the help of digital cultures. 
Regionality or regional elements are determining factors as far as the character formation of individuals is concerned. However, it may be replaced with a common perspective with the increase of sharings in media and interaction. New media allows individuals to be committed to a society while finding the chance to represent and express themselves. And it matches up well with the concept of network society. New media with features like interaction, digitilization and virtuality adds a new value to itself with the multimedia products shared through the regional aspects of creativity. The individuality aspect is added to the new media featurte as a result of individuals' sharings. The formation of network society accelerates through the addition of individuality aspect to the characteristic features of the new media, and the number of the digital based individuals increase with technocrats. The individuality aspect here increases the interaction with large sharings, and thus the regional creativity produces its products in the new media in a faster and easier way with a better connection aided by the interaction feature and proceeds on its way by regenerating itself.

\section{REFERENCES}

Alemdar, K. and Erdoğan, İ. (1994). Popüler Kültür ve İletişim. Ankara: Ümit Yayıncılık.

Bens, E. Golding, P. and McQuail, D. (2005). Communication Theory and Research. London: Sage Publication.

Berger, A. A. (1998). Media Research Techniques. California: Sage Publication.

Bohm, D. (1998). On Creativity (Edited by Lee Nichol). London: Routledge.

Burges, J. (2007). Vernacular Creativity and New Media. Doctor of Philosophy Thesis, University of Queensland, Creative Industries Faculty.

Burgess, J. (2006). Re-mediating Vernacular Creativity: Digital Storytelling, First Person: International Digital Storytelling Conference, Australian Centre for the Moving Image, Melbourne, Australia.

Castells, M. (1989). The Informational City. Oxford: Basil Blackwell.

Castells, M. (2010). The Rise of The Network Society. London: Wiley \& Blackwell.

Dijk, J. V. (2005). The Deepending Divide: Inequality in The Information Society. London: Sage Publication.

Dijk, J. V. (2006). The Network Society: Social Aspects of New Media. London: Sage Publication.

Dizard, W. (1999). Old Media New Media. United States: Longman.

Edensor, T. and Leslie D. (2010). Spaces of Vernacular Creativity: Rethinking The Cultural Economy. New York: Routledge.

Laughey, D. (2007). Key Themes in Media Theory. Berkshire: Open University Press.

Lievrouw L. and Livingstone S. (2002). Handbook of New Media. London: Sage Publication.

Littlejohn, S. ve Foss, K. (2009). Encyclopedia of Communication Theory. London: Sage Publication.

Lister, M. Dovey and Others. (2003). New Media: A Critical Introduction. New York: Routledge.

Lyon, D. (1988). The Information Society: Issues and Illusions. Cambridge: Blackwell Publishers.

Manovich, L. (2001). The Language of New Media. Cambridge: MIT Press.

McQuail, D. (2005). McQuail's Mass Communication Theory. London: Sage Publication.

McQuail, D. and Windahl, S. (1993). Communication Models. London: Longman.

Severin, W. and Tankard, J. (1992). Communication Theories: Origins, and Uses In The Mass Media. London: Longman.

Vivanco, E. and Verghese, G. (2010). Vernacular Design: Moving Towards a Symbolic Relationship Between Local and Global Commoditization. DesignEd Asia Conference. Hong Kong.

Webster, F. (2006). Theories of The Information Society. USA: Routledge.

Wright, C.R. (1959). Mass Communication: A Sociological Perspective. New York: Random House. 
The Turkish Online Journal of Design, Art and Communication - TOJDAC July 2011 Volume 1 Issue 1

Yengin, D. (2010). New Media and Conversion of Reality, International Symposium Communication in the Millennium. Eskişehir. 318-331. 